\title{
Sporadic sodium and E layers observed during the summer 2002 MaCWAVE/MIDAS rocket campaign
}

\author{
B. P. Williams ${ }^{1}$, C. L. Croskey ${ }^{2}$, C. Y. She ${ }^{3}$, J. D. Mitchell ${ }^{2}$, and R. A. Goldberg ${ }^{4}$ \\ ${ }^{1}$ Northwest Research Associates, Colorado Research Associates division, Boulder, CO, USA \\ ${ }^{2}$ Communications and Space Sciences Laboratory, Electrical Engineering Department, Pennsylvania State University, \\ University Park, Pennsylvania, USA \\ ${ }^{3}$ Department of Physics, Colorado State University, Fort Collins, Colorado, USA \\ ${ }^{4}$ NASA/Goddard Space Flight Center, Laboratory for Solar and Space Physics, Greenbelt, MD, USA
}

Received: 10 October 2005 - Revised: 21 February 2005 - Accepted: 4 May 2006 - Published: 3 July 2006

Part of Special Issue "MaCWAVE: a rocket-lidar-radar program to study the polar mesosphere during summer and winter"

\begin{abstract}
On 5 July 2002, a MaCWAVE (Mountain and Convective Waves Ascending VErtically) payload launched from Andøya Rocket Range, Norway, observed narrow enhanced layers of electron density that were nearly coincident with sporadic sodium layers measured by the Weber sodium lidar at the nearby ALOMAR Observatory. We investigate the formation mechanism of these layers using the neutral wind and temperature profiles measured directly by the lidar and the vertical motion deduced from the sodium mixing ratio. Through comparisons of the lidar data to the sporadic $\mathrm{E}$ in situ data, we find support for the concentration and downward motion of ions to an altitude where chemical models predict the rapid conversion of sodium ions to neutral sodium.
\end{abstract}

Keywords. Atmospheric composition and structure (Ion chemistry of the atmosphere; Thermosphere-composition and chemistry) - Ionosphere (Ionospheric irregularities)

\section{Introduction}

Sporadic-E layers (Es) have been observed for many years by ionosondes, incoherent scatter radars, and rockets. They are narrow layers of ionization in the E-region of the ionosphere usually occurring at altitudes between 90 and $120 \mathrm{~km}$. Compression of the ionic material from meteoric debris into thin layers has been classically described by Whitehead (1961), Axford (1963), Smith and Miller (1980), and numerous others. "Wind-shear theory" predicts a "pileup" of positive ions in the vertical shear region of the horizontal wind. Sporadic

Correspondence to: $\mathrm{B}$. P. Williams

(biff@cora.nwra.com) sodium layers $\left(\mathrm{Na}_{\mathrm{s}}\right)$ are narrow layers of neutral sodium occurring in a similar altitude range. They have long been shown to be correlated with sporadic-E layers (Kwon et al., 1988; von Zahn and Hansen, 1988) and may be produced by the conversion of sodium ions in the sporadic-E layer to neutral sodium (Cox and Plane, 1998).

The summer MaCWAVE (Mountain and Convective Waves Ascending VErtically) program included the launching of instrumented Terrier-Orion rockets on 1 and 5 July 2002. These two rockets carried probes to measure the electron and ion density profiles and associated fluctuations. The basic results were presented in Croskey et al. (2004), with a concentration on the profiles and turbulence between 80 and $90 \mathrm{~km}$. This paper discusses the enhanced electron concentrations above $90 \mathrm{~km}$ for the 5 July 2002 rocket flight that we believe to be due to sporadic E layers. The Weber sodium lidar was also operating and observed sharp sodium density gradients during the evening of 1/2 July 2002 (Fritts et al., 2004) and a sporadic sodium layer on 5 July 2002. Williams et al. (2004) studied the vertical motion of the sporadic sodium layer to determine the vertical displacement spectrum due to gravity waves. The sodium density during the 1 July MaCWAVE launch was modified by the presence of charged ice particles associated with polar mesospheric clouds and polar mesosphere summer radar echoes (She et al., 2005) and will not be reported here. This paper will concentrate on the correlation between the sporadic sodium and E layers and the dynamics and plasma physics that produced the layers on 5 July 2002.

\subsection{Previous in situ observations of sporadic-E}

Classic wind-shear theory has been verified a number of times by in situ measurements of the electron density within

Published by Copernicus GmbH on behalf of the European Geosciences Union. 
sporadic-E layers at midlatitudes. For example, Smith (1970) described the results of a number of early flights conducted from Wallops Island, Virginia. Two layers were observed, with the upper layer descending with time, e.g., descending from $140 \mathrm{~km}$ to $103 \mathrm{~km}$ in a 6-h interval. The width of the descending layer decreased during this time, with a compensating increase in electron density, implying an approximate constant columnar electron density. During the same time period, a more irregular lower layer had electron density values in the $3.5 \times 10^{4} \mathrm{~cm}^{-3}$ to $7.5 \times 10^{4} \mathrm{~cm}^{-3}$ range with a layer half-width of about $1 \mathrm{~km}$. Application of wind-shear theory to the descending intermediate layer was able to reproduce the observations fairly well, but it was not as successful for the lower, more irregular layer (Constantinides and Bedinger, 1971; Fujitaka et al., 1971; Smith and Mechtly, 1972).

Confirmation of the predictions of wind-shear theory at midlatitudes was also provided by one of the two sounding rocket flights in the SEEK campaign (Yamamoto et al., 1998) A swept-frequency impedance probe on one flight was used to observe the electron density concentration, while a trimethyl aluminum (TMA) chemical release (Larsen et al., 1998) permitted observation of the neutral winds. The second SEEK rocket used a Langmuir probe for electron density measurement (Mori and Oyama, 1998, 2000). A TMA release was not included on this second rocket, and thus wind measurements were not available and a direct evaluation of wind-shear theory could not be made for that flight.

Similarly, neutral wind data were not available for the flight from Wallops Island, Virginia, described by Kelley et al. (1995). A single-point absolute calibration of the fixed-bias Langmuir probe was provided by a collocated ionosonde, and the sporadic-E layer reached a peak concentration of $1 \times 10^{6} \mathrm{~cm}^{-3}$. The apogee for this particular flight was deliberately kept low; as a result, the horizontal velocity of the payload was much larger than the vertical velocity. Much of the additional structure in the electron density seen above the layer was attributed to horizontal variations.

Although measurement of the neutral wind field by a TMA chemical release had been planned as part of an experiment in 1998, only the instrumented rocket was launched (Earle et al., 2000). This payload included a mass spectrometer, which enabled identification of $\mathrm{Fe}^{+}, \mathrm{Mg}^{+}$, and combined $\mathrm{NO}^{+}, \mathrm{O}_{2}^{+}$sublayers within the sporadic-E layer. Earle et al. (2000) were able to work backward from the observed altitude spread of the sublayers to a consistent estimate of the neutral wind structure.

While numerous ground-based studies of Es layers have been made through ionosonde and incoherent scatter radar measurements at high latitudes (cf. Mathews 1998; Kirkwood and Nilsson, 2000), there have only been few cases of direct in situ measurements. For example, the results from Langmuir probes carried on seven rocket flights were reported by Reddy et al. (1969). Two of the flights were accompanied by chemical vapor trail releases for the measure- ment of horizontal winds. Although moderately strong wind shears were present, no sporadic-E was observed.

During another rocket flight, in situ measurements of an Es layer made by a quadrupole mass spectrometer (von Zahn et al., 1989) demonstrated the presence of a double ion layer with a vertical separation of about $5 \mathrm{~km}$. The relative concentration of the metallic ions in both layers was essentially the same; $\mathrm{Fe}^{+}$was the most abundant, followed by $\mathrm{Mg}^{+}$and then $\mathrm{Na}^{+}$. The $\mathrm{Mg}^{+} / \mathrm{Na}^{+}$abundance ratio was about 10 .

Four sounding rockets carried quadrupole mass spectrometers during separate evenings of the ROSE campaign through the E region, one of which observed a thin $(<1 \mathrm{~km})$ Es layer at $91.5 \mathrm{~km}$ superimposed on top of a broader $(22 \mathrm{~km}$ layer). The measurements of the metallic ion concentrations showed that the $\mathrm{Fe}^{+}$layer was only a few hundred meters above the $\mathrm{Mg}^{+}$layer (Steinweg et al., 1992).

The METAL campaign (Kirkwood and von Zahn, 1991), which was conducted from Andøya Rocket Range, Norway, has to date provided the most complete study of high-latitude sporadic-E and neutral layers. Neutral Fe layers were observed by a ground-based lidar; EISCAT was used to measure electron densities and electric fields; ionosondes monitored the condition of the ionosphere; sounding rockets carried positive ion probes and a mass spectrometer; and chaff releases from meteorological rockets were used to observe the winds below $100 \mathrm{~km}$. The rocket-borne plasma probes observed weak Es layers on three nights of the campaign. Es layers were also recognized on five additional evenings without rocket support from study of the ionosonde and EISCAT data. While a simple wind shear was sufficient to describe the observed Es layer in one case, the other seven observations required the presence of electric fields to properly understand the Es formation. The data from the mass spectrometer flight showed a weak $\mathrm{Fe}^{+}$layer a few hundred meters above a $\mathrm{Mg}^{+}$ layer (Alpers et al., 1993).

Because the underlying physics is more complicated at high latitudes, the original formulation of wind-shear operation has to be expanded to properly describe Es formation at these latitudes. This is because the Earth's magnetic field is nearly vertical at high latitudes and additional ion convergence mechanisms can exist as described in the next section.

\subsection{Wind shear theory of sporadic-E generation}

Early formulations of wind-shear theory for the creation of sporadic-E (Whitehead, 1961; Axford, 1963) did not include the effects of electric fields and have been shown to be adequate, if not complete, at midlatitudes (Whitehead, 1971). However at high latitudes, the magnetic dip angle is much larger and electric fields can become the largest drivers of ion motion (Nygrén et al., 1984; Kirkwood and von Zahn, 1991; and others).

For completeness we now briefly outline the various terms that produce the vertical ion motion. Using the notation of Kirkwood and Nilsson (2000), the vertical ion velocity for 
the Northern Hemisphere when electric fields and winds are included is given by Eq. (1):

$$
\begin{aligned}
& v_{i z}=\frac{\cos I}{1+\rho_{i}^{2}}\left[\frac{E_{E}}{B_{0}}-W_{N} \sin I\right] \\
& +\frac{\rho_{i} \cos I}{1+\rho_{i}^{2}}\left[-\frac{E_{N}}{B_{0}}+W_{E}\right] \\
& +\left[1-\frac{\cos ^{2} I}{1+\rho_{i}^{2}}\right] W_{Z} \\
& -\frac{\Omega_{e} \Omega_{i}}{\Omega_{e} v_{i}+\Omega_{i} v_{e}}\left[\frac{1}{n_{i}} \frac{d\left(n_{i} k T\right)}{d z}\right] \frac{2}{e B_{0}}\left(\sin ^{2} I+\frac{v_{e} v_{i} \cos ^{2} I}{v_{e} v_{i}+\Omega_{e} \Omega_{i}}\right)
\end{aligned}
$$

where $I$ is the magnetic dip angle and $E_{E}$ and $E_{N}$ are the eastward and northward components of the electric field. Similarly, $W_{E}$ and $W_{N}$ are the eastward and northward components of the neutral wind field. $W_{Z}$ is the vertical component of the neutral wind, and $B_{0}$ is the strength of the magnetic field. $\mathrm{k}$ is Boltzman's constant and $T$ is the neutral temperature. ( $T_{e}=T_{\text {ion }}=T_{\text {neutral }}$ has been assumed.) $\Omega_{i}$ is the (metallic) ion gyro frequency, $v_{i}$ is the corresponding ion-neutral collision frequency, and $\rho_{i}=v_{i} / \Omega_{i}$. Similarly, $\Omega_{e}$ is the electron gyro frequency, and $v_{e}$ is the electron-neutral collision frequency. The effects of gravity have been ignored in Equation 1 since they produce little effect at altitudes below $300 \mathrm{~km}$ (Bedey and Watkins, 1997). Finally, $n_{i}$ is the metallic ion density, which is inferred from the experimentally observed electron density as described in a following section.

1.3 Generation of neutral sodium from concentrated ion layers

According to one current theory (Cox and Plane, 1998), once the metallic ions are concentrated in layers by the wind shear theory, they can be moved downwards following wave phase progression or by electric fields. $\mathrm{As} \mathrm{Na}^{+}$moves downwards, its chemical lifetime decreases from more than a day at $100 \mathrm{~km}$ to minutes at $90 \mathrm{~km}$ and the $\mathrm{Na}^{+}$is rapidly converted into neutral $\mathrm{Na}$ that can be observed by a sodium lidar. This theory has been found to accurately model most sporadic layers observed by the sodium lidar and incoherent scatter radar over Arecibo (Collins et al., 2002). The situation at high latitudes is more complicated, however, by the additional effect of electric fields on the ion layers and the absorption of both neutral sodium and charged particles onto the surface of ice particles. In a case study using measurements and simulations, Heinselman (2000) found that a sporadic sodium layer could form via the Cox and Plane (1998) chemical method and that the layer could be moved around by auroral ionization.

\section{Instruments and observations}

\subsection{Rocket instrument configuration}

The large instrumented payloads of the MaCWAVE program were primarily designed for the observation of plasma densities and irregularities in the mesosphere and lower thermosphere (MLT). Both the forward and aft ends of each payload contained an axially mounted fixed-bias Langmuir probe and two impact ionization detectors. The impact detectors were used to determine the presence of ice particles in PMSE/NLC regions (Mitchell et al., 2005). During the upleg portion of each flight both Langmuir probes collected electrons (one in the ram and the other in the wake), while the polarity of one instrument was switched at apogee so that positive ions were collected in the ram during the downleg.

Absolute calibration of the observed electron densities for the upleg trajectory was performed by use of an on-board Faraday rotation radio propagation experiment (Jacobsen and Friedrich, 1979). During the downleg portion of the flight, the ray path geometry was not optimum and precluded direct electron density calibration. A more complete description of the operation of the Langmuir instruments is provided in Croskey et al. (2006). In this paper we focus on the Langmuir probe measurements for altitudes above $90 \mathrm{~km}$, particularly in the sporadic-E region.

In addition, many inflatable falling sphere flights were used to measure the neutral winds and temperatures over several-hour periods before and after the launch of the large instrumented rockets.

\subsection{Lidar configuration}

The ground-based Weber sodium lidar located at the range simultaneously observed the structure and motion of the neutral sodium layer during the times of the launches. The sodium lidar also provided measurements of the zonal winds and temperatures during the time of the launch of the large instrumented rocket. The Weber lidar measures sodium density, temperature, and radial wind by transmitting two $0.5-\mathrm{W}$ beams with a wavelength of $589 \mathrm{~nm}$ that resonantly scatter from the atmospheric sodium layer located at roughly 80 $105-\mathrm{km}$ altitude. The backscattered Na light was collected by two 1.8-m steerable telescopes (provided by the RayleighMie Raman (RMR) lidar team) that are designed to simultaneously and independently receive the signals of the sodium and RMR lidars. We shifted the frequency of the transmitted beams up and down by $630 \mathrm{MHz}$ every second and third pulse, respectively, with a pulse repetition rate of $50 \mathrm{~Hz}$ to measure the Doppler shift and broadening of the atmospheric sodium spectrum and determine temperature, radial wind, and sodium density. The sodium density was calibrated by normalizing our photon profiles to get the appropriate atmospheric density between 30 and $40 \mathrm{~km}$ for the latitude and season. The atmospheric density in the stratosphere varies 


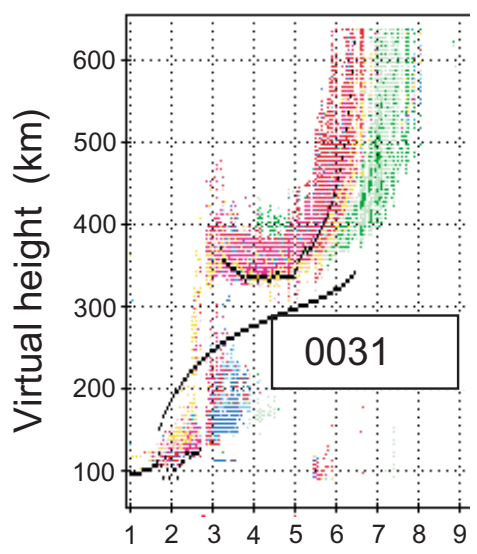

Frequency $\mathrm{MHz}$

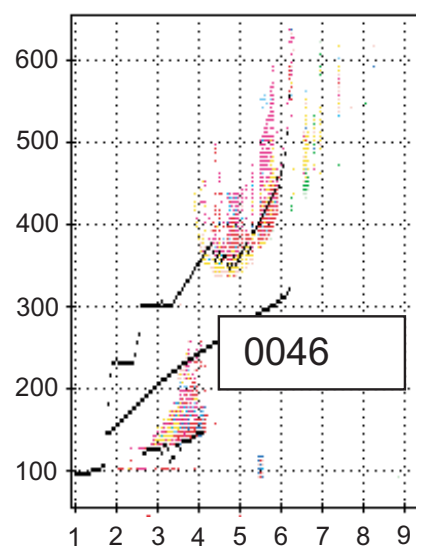

Frequency $\mathrm{MHz}$

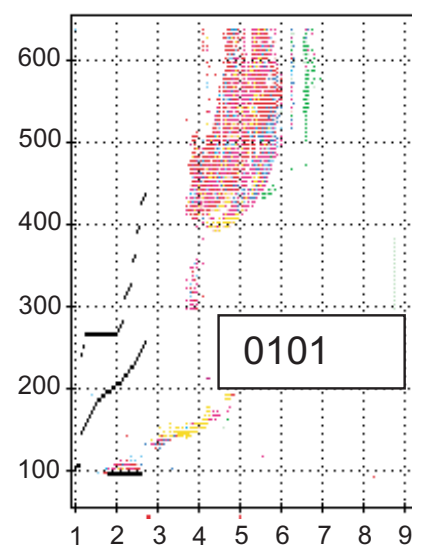

Frequency $\mathrm{MHz}$

Fig. 1. Digisonde data from Troms $\varnothing$, Norway for 5 July 2002. Notice the development of the layer below $100 \mathrm{~km}$.

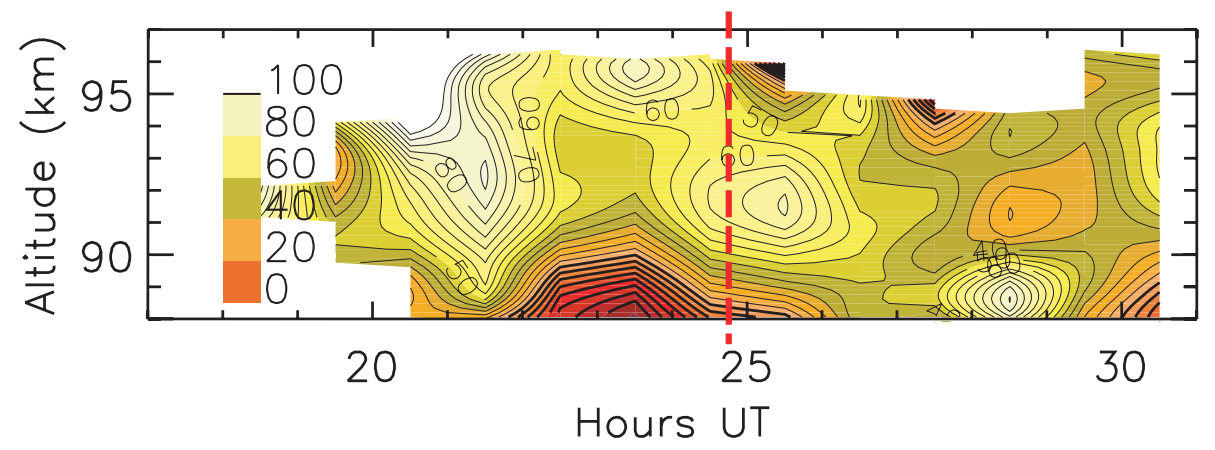

Fig. 2. Observed zonal winds during the night of 4/5 July, 2002. The vertical red line indicates the time of the launch of the large instrumented rocket.

much less than the sodium density. Beam 1 was oriented at $20^{\circ}$ west of zenith and Beam 2 was pointed $20^{\circ}$ east of zenith (geographic coordinates) for this campaign, allowing us to measure sodium density, zonal wind and temperature profiles at two locations separated by $62 \mathrm{~km}$ horizontally at $90 \mathrm{~km}$ altitude.

\subsection{Data presentation}

We now describe our observations of a very thin Es layer that was measured during the upleg portion of the 5 July 2002 rocket flight (NASA flight number 41.033). The thin Es layer was not observed during the downleg portion of the flight, which was displaced horizontally by about $50 \mathrm{~km}$ to the northwest from the upleg traversal of the sporadic-E region. This implied horizontal spatial variation limits some of the conclusions that we can make. The instrumented rocket flight provided a high-resolution snapshot at one particular time, while the multiple falling sphere flights and continuously operating sodium lidar offered a more continuous monitoring of the motions of the neutral atmosphere.
Unfortunately, the EISCAT incoherent scatter radar data is not available for the time interval of the launch (00:47 UT) of the Flight 41.033. Data from the Troms $\varnothing$ Digisonde, which is located $\sim 137 \mathrm{~km}$ to the east of the rocket flight path, are shown in Fig. 1. After the sporadic-E layer was fully developed, its virtual height was identified as $95 \mathrm{~km}$ by the automatic curve fitting routine.

As described by Williams et al. (2004), significant gravity wave activity was present in the lower thermosphere and upper mesosphere during the 4/5 July observation period. These gravity waves produced variations in the zonal wind throughout the evening (Fig. 2).

The data used to produce Fig. 2 are one-hour averages of the lidar returns. In general, the wind structure changed considerably during the eight hours of sodium lidar operation (Fritts et al., 2004). As can be seen in the figure, the zonal wind rapidly reduced in magnitude in the $96-97 \mathrm{~km}$ region around the time of the launch, with a more constant wind structure at $93 \mathrm{~km}$. Figure 3 shows the vertical distribution of the zonal wind for a time interval centered on the time of the launch (blue line). (The gray line represents the wind 
from an earlier rocket campaign and will be discussed in a following section.) We would expect that this wind shear is related to the formation of the Es layer.

The data from the sodium lidar also show that a sporadic sodium layer developed shortly after the launch of the main rocket (Fig. 4). As Fig. 4 indicates, the $\mathrm{Na}_{\mathrm{s}}$ layer developed just below $95 \mathrm{~km}$ and continued downward for the next several hours. Assuming that the $\mathrm{Na}_{\mathrm{s}}$ layer is a tracer of the background neutral motion (and ignoring any possible horizontal advection), the inferred vertical motion is small, being on the order of $-0.9 \mathrm{~m} / \mathrm{s}$.

Figure 5 presents the Na lidar data in an alternate format. In this figure, the " $\mathrm{X}$ " locates the position and time of an upper Es layer observed in the Langmuir probe data. A small " $\mathrm{X}$ " located $1 \mathrm{~km}$ below the large " $X$ " represents a smaller secondary Es layer also observed in the rocket data. In the same figure, the color shading shows the sodium mixing ratio for the west lidar beam while the black contour lines show the sodium mixing ratio for the east beam. The sodium mixing ratio is defined as the sodium density divided by total atmospheric density. The atmospheric density is calculated from the measured temperature profile as described in Williams et al. (2002). If there is no source of sodium and no horizontal advection, the sodium mixing ratio is conserved in each parcel, and contours of the mixing ratio follow the vertical motion. The difference between the two beams gives an estimate of the horizontal variations in the time and height of the layers. The two beams show the same structure at longer periods but different structures on small time and spatial scales likely due to gravity waves with horizontal wavelengths smaller than the beam separation. Williams et al. (2004) shows that the vertical displacement spectra of both beams follow the form expected for gravity wave modulation of the sodium layer. The downward motion of the enhanced mixing ratio in the west beam is about 5 min earlier than in the east beam, possibly due to a phase difference of the perturbing wave at the two beam locations. We assume that the downward movement of the structure in the sodium mixing ratio represents the mean vertical wind; the red line on the figure corresponds to a vertical velocity of $-0.9 \mathrm{~m} / \mathrm{s}$.

During the upleg portion of the rocket flight, the Langmuir probe was biased at +5 Volts to collect electrons. As has been mentioned, an on-board radio propagation experiment provided by M. Friedrich of the Graz University of Technology was used to provide an absolute calibration of the measured electron density. The background unperturbed electron density was subtracted from the observed profile to produce the "excess electron" profile shown in Figs. 4 and 6. The corresponding metallic ion density was inferred by following the procedure described by Smith and Miller (1980) and presented here.

The experimental data are the measurements of electron number density, $N_{e}$. The density of the molecular ions, $\mathrm{N}_{\text {ion }}$, is assumed equal to $N_{e}$ above and below the sporadic-E layer. An $N_{\text {ion }}$ profile is interpolated through the sporadic-E layer

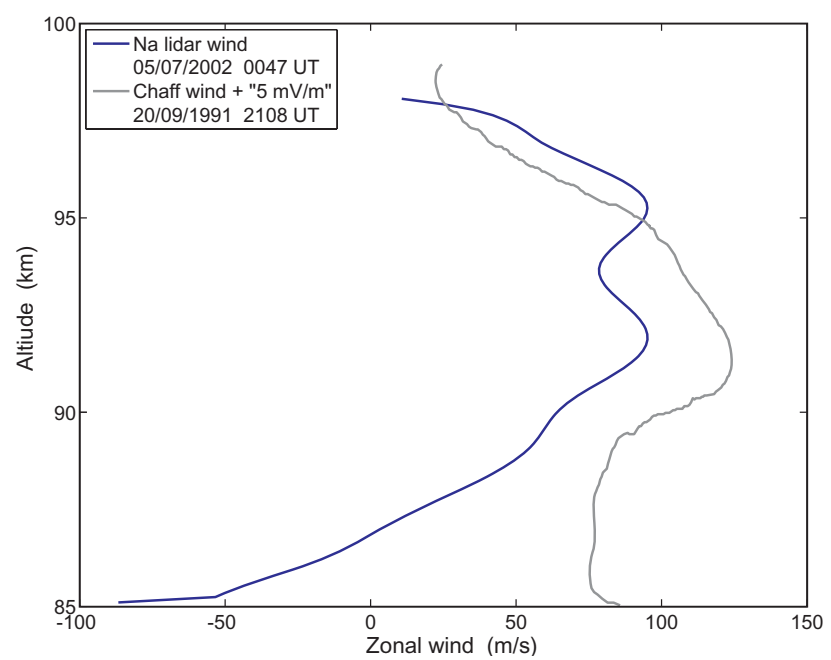

Fig. 3. Average of the zonal wind observed by the Na lidar for a one-hour interval centered around the time of the MaCWAVE rocket launch. The data for the gray line is taken from Kirkwood and von Zahn, 1993 and represents measured wind plus the effect of a $5 \mathrm{mV} / \mathrm{m}$ southward electric field.

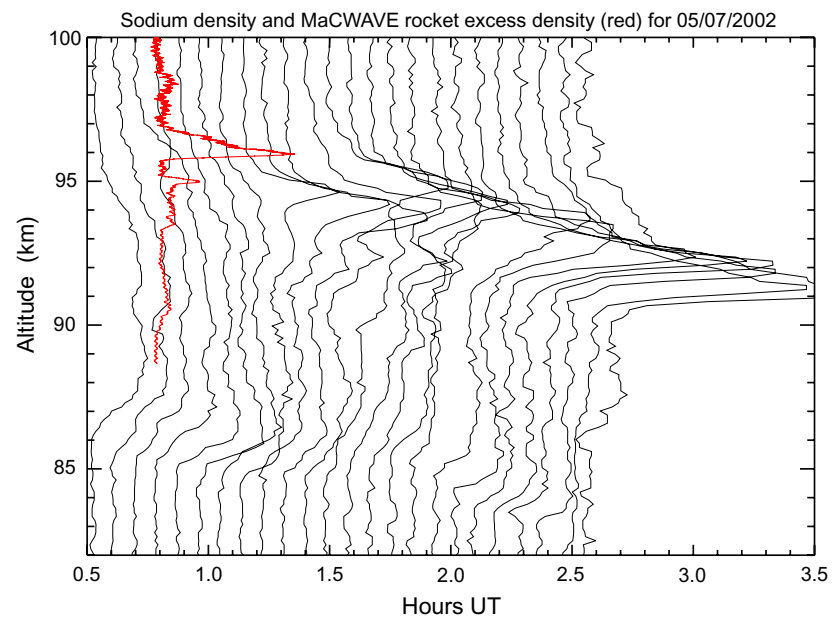

Fig. 4. Sodium lidar observation of the development of a descending sudden sodium layer shortly after the launch of the instrumented rocket. The excess electron density observed by the rocket during the traversal of the sporadic-E layer is shown in red. One hour corresponds to $5000 \mathrm{Na} / \mathrm{cm}^{3}$ and $10^{5}$ electrons $/ \mathrm{cm}^{3}$.

region and would be the molecular ion concentration if the sporadic-E layers were not present. Because the lifetime of molecular ions is very short compared to transport times or the metallic ion lifetime, in photoequilibrium the molecular ion production $(\mathrm{Q})$ is equal to the loss $(\mathrm{L})$ as determined by an effective ion-electron recombination rate, $\alpha$.

$Q=\alpha N_{i o n}^{2}$

This ion production rate will not be changed by the presence of a metallic ion layer. On the other hand, the increase in 


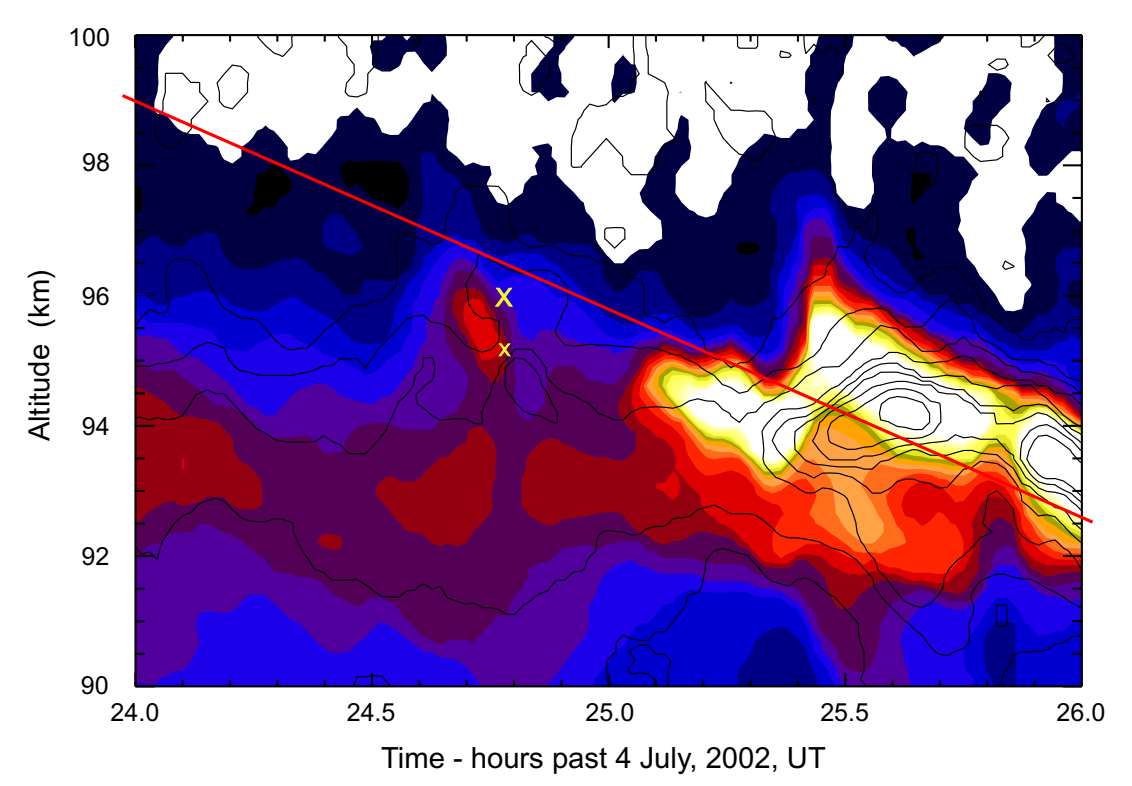

Fig. 5. The sodium mixing ratio is shown for beam 1 with the color contours and for beam 2 with the black line contours for the evening of 4/5 July 2002. The large X and small x identify the upper and lower sporadic-E layers, respectively, at the time of the in situ rocket-borne observation. The red line provides one estimate of the vertical wind velocity.

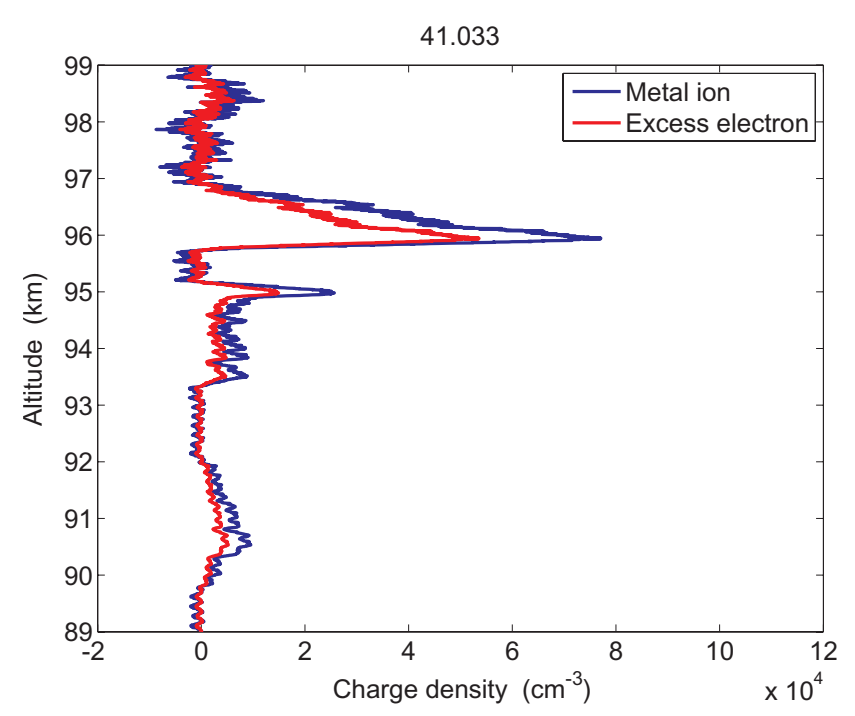

Fig. 6. Measured excess electron density and corresponding metallic ion density associated with the sporadic-E layer.

electron concentration associated with the sporadic-E layer tends to increase the loss rate and the molecular ion concentration will be reduced so that photoequilibrium is maintained. Now

$Q=\alpha\left(N_{e}-n_{i}\right) N_{e}$

where $n_{i}$ is the metallic ion density, and the term $\left(N_{e}-n_{i}\right)$ is the molecular ion density in the layer as required by charge neutrality. When Eqs. (2) and (3) are combined, the metallic ion density can be explicitly determined.

$n_{i}=\frac{N_{e}^{2}-N_{i o n}^{2}}{N_{e}}$

The depression of the molecular ion concentration, $\left(N_{e}-n_{i}\right)$, inside the sporadic-E layer has been confirmed by a mass spectrometer measurement during a midlatitude rocket flight (Roddy et al., 2004). The inferred excess electron density and corresponding metallic ion density are shown in Fig. 6. We note that although the excess electron density and the metallic ion density could be assumed to be equal initially, this condition will not satisfy Eqs. (2) and (3). Once photoequilibrium is reached, the model shows that both the final electron and molecular ion densities are modified by the presence of the metallic ions. The peak metallic ion density was roughly $8 \times 10^{4} \mathrm{~cm}^{-3}$ for the main peak and $2.5 \times 10^{4} \mathrm{~cm}^{-3}$ for the smaller peak. The peak sporadic sodium density was roughly $1500 \mathrm{~cm}^{-3} 30 \mathrm{~min}$ after the rocket flight and $5000 \mathrm{~cm}^{-3} 2 \mathrm{~h}$ later. This gives a Na/ion ratio of $2-6 \%$ for the larger ion peak and 6-20\% for the smaller ion peak. These two ratio ranges are both possible, so it doesn't help distinguish which ion peak gave rise to the $\mathrm{Na}_{\mathrm{s}}$ layer.

\section{Discussion}

As a result of the strong dependence of the ion-neutral collision frequency on altitude, the relative importance of each of the four terms on the right-hand side in Equation 1 also varies with altitude. At the primary altitude of interest $(96 \mathrm{~km})$, 
evaluation of a number of terms in Eq. (1) produces a simplified result.

$$
\begin{aligned}
& v_{i z} \approx 2.2 \times 10^{-5}\left[\frac{E_{E}}{B_{0}}-W_{N} \sin I\right] \\
& +2.2 \times 10^{-3}\left[-\frac{E_{N}}{B_{0}}+W_{E}\right] \\
& +1.0 W_{Z} \\
& -0.034\left[\frac{1}{n_{i}} \frac{d\left(n_{i} T\right)}{d z}\right]
\end{aligned}
$$

From Eq. (5), one can see that the effects of $E_{E}$ and $W_{N}$ (term (5a)) are negligible in this region. The application of the simple wind-shear theory requires a balance between the effects from the sum of zonal wind and northward E field terms (5b) and the sum of tidal and gravity wave motion (5c) against the ion diffusion (5d). However, this balance isn't always required because as the ion layer descends, it may be "dumped" at a low altitude if the ion vertical motion cannot keep up with the phase speed of the driving gravity wave (Chimonas and Axford, 1968).

The ion diffusion term (5d) depends on both the absolute concentration and gradient of the ion density. Evaluation of Eq. (5d) requires a differentiation of the ion density profile (left panel of Fig. 7), which was modulated at the payload roll rate. As a result, the calculated ion diffusion shows some artifacts related to the payload motion. The right panel of Fig. 7 does show "nulls" in the vertical metallic ion velocity at 95 and $96 \mathrm{~km}$; however, once "dumping" has started, these nulls don't necessarily have to match the nulls of the vertical ion wind.

Finding a balance between terms (1b), (1c), and (1d) (or terms $(5 b),(5 c)$, and $(5 d))$ is problematic in this case. We can expect that the background vertical wind, which is used in term (1c), will be greatly dependent on the gravity wave activity, and large gravity waves were present during this time (Williams et al., 2004; Fritts et al., 2004). Based on the rate of descent of the $\mathrm{Na}_{\mathrm{s}}$ in Figs. 4 and 5, we estimate a mean vertical velocity of $-0.9 \mathrm{~m} / \mathrm{s}$.

The normalized ion collision frequency, $\rho=v_{i} / \Omega_{i}$, becomes exponentially large as the ion layer descends, and as a result, the downward ion motion is reduced, even if the winds and electric fields remain constant. Eventually a "dumping" of ions into a more permanent layer occurs when the ion velocity becomes so small that the ions can no longer follow the node of the wind structure (Chimonas and Axford, 1968). The computer simulations of Kirkwood and von Zahn (1993) demonstrate this effect as ion trajectories that increasingly lag behind the descending wind node. These model simulations also show that if only a tidal zonal wind is present, up to $24 \mathrm{~h}$ may be required to bring metallic ions down from 120 to below $100 \mathrm{~km}$. However, the model also shows that a southward electric field (part of Eq. (1b)) can greatly increase the downward velocity and the rate of layer production.
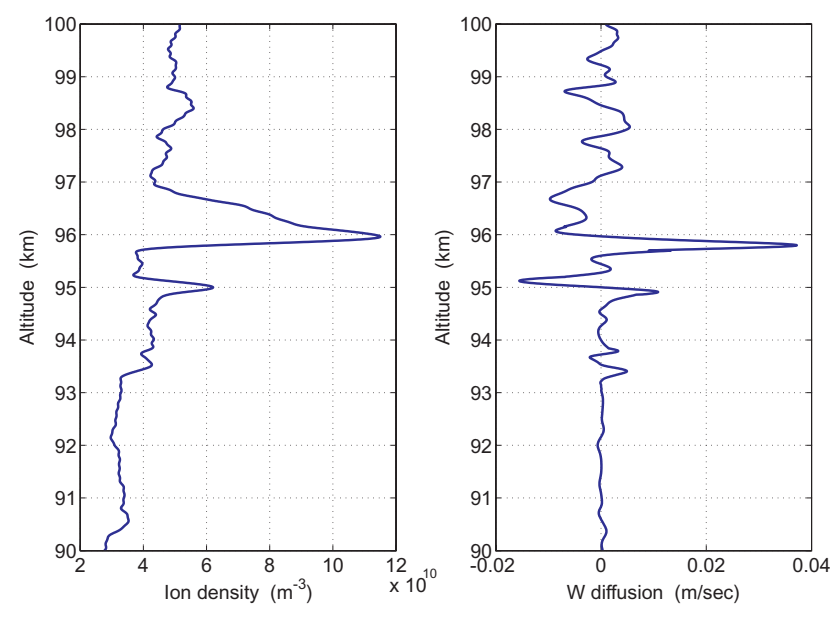

Fig. 7. Observed ion density (left panel) and corresponding vertical ion motion (right panel).

The mass spectrometer data from the METAL campaign at Andøya Rocket Range, Norway, (Alpers et al., 1993; Kirkwood and von Zahn, 1993) identified a $\mathrm{Mg}^{+}$layer about $600 \mathrm{~m}$ beneath a much smaller $\mathrm{Fe}^{+}$layer that was located at $96 \mathrm{~km}$. As shown in Fig. 7, the ion density of the lower Es layer in this MaCWAVE flight is smaller than that of the upper layer, which is located at $96 \mathrm{~km}$. The model of Kirkwood and von Zahn (1993) was able to reproduce the observed metal ion layer heights if an empirically determined southward electric field of about $5 \mathrm{mV} / \mathrm{m}$ was added to the wind profile that had been measured by radar tracking of falling chaff from a meteorological support rocket. We have taken the published chaff wind data from Kirkwood and von Zahn (1993) and added to it the equivalent wind $\left(-E_{N} / B_{0}\right)$ term to produce the gray line in Fig. 3. If the effect of a $1 \mathrm{mV} / \mathrm{m}$ northward $\mathrm{E}$ field is added to the Na lidar wind data, the two wind profiles of Fig. 3 would effectively line up at $96 \mathrm{~km}$. However even without that adjustment we believe that the MaCWAVE program wind profile is similar enough to the adjusted METAL program wind profile to use the model simulations of Kirkwood and von Zahn (1993) to understand the MaCWAVE Langmuir probe Es data. Although $\mathrm{Mg}^{+}$was more abundant than $\mathrm{Fe}^{+}$for the METAL measurement by a ten-to-one ratio (Alpers et al., 1993), other high-latitude mass spectrometer measurements have shown a four-to-one concentration ratio (von Zahn et al., 1989) or a one-to-one ratio (Steinweg et al., 1992). We also note that, at midlatitudes, four-to-one (Aikin et al., 1974), one-to-four (Roddy et al., 2004), and one-to-three (Earle et al., 2000) $\mathrm{Mg}^{+} / \mathrm{Fe}^{+}$density ratios have been observed. The data of Fig. 6 indicate a one-to-three density ratio for the MaCWAVE flight. Because the mass numbers of $\mathrm{Na}^{+}$and $\mathrm{Mg}^{+}$are so similar, there is little height discrimination between these two species, and we must attribute the lower Es layer to both ions. Since the coefficient of term $1 \mathrm{~b}$ determines the balance of the various 
wind contributions, it is useful to consider its evaluation for both heavy and light ions. The value shown in term $5 \mathrm{~b}$ is $2.2 \times 10^{-3}$ for $\mathrm{Fe}^{+}$; the same value occurs at about $95.1 \mathrm{~km}$ for $\mathrm{Na}^{+}\left(\right.$or $\left.\mathrm{Mg}^{+}\right)$. This is essentially the same altitude difference between the two Es layers shown in Fig. 7.

The only significant difference in the wind comparison of Fig. 3 is the presence of a $3.3-\mathrm{km}$ gravity wave in the Na lidar wind data. Turunen et al. (1993) attribute the very rapid downward movement of observed high latitude Es layers to the presence of gravity waves with a period of about $1 \mathrm{~h}$. Such variation of the zonal wind has been shown (Chimonas and Axford, 1968; Mathews and Bekeny, 1979) to modulate the ultimate dumping height for the ions. Because the instrumented rocket measurement provides only a snapshot of the Es structure, we do not have an observation of such modulation. However there is an intriguing possibility that $96 \mathrm{~km}$ was not the final dumping altitude for the metallic ions. Chimonas and Axford (1968) show that for some combinations of modulation of the zonal winds by gravity waves and steady vertical winds (as generated by a constant $E$ field), the modulation of the dumping height follows a "sawtooth" pattern. The general picture is that when the ion velocity has been sufficiently reduced due to more frequent ion-neutral collisions, the ions can no longer follow the phase velocity of the gravity wave. The background vertical wind then moves the newly freed ions upward, their mobility increases, and they are once again trapped by the downward node of the gravity wave-producing the next downward slope of the sawtooth. This cycle could repeat for a number of cycles if the driving gravity wave is sustained.

We also observe a similar structure in the plot of the height of the $\mathrm{Na}_{\mathrm{s}}$ layer that was given by Williams et al. (2004). Inspection of that plot reveals a sawtooth time dependence with a period of about one hour. In the discussion of Sect. 2.3 we have estimated a downward phase velocity of $0.9 \mathrm{~m} / \mathrm{s}$ for the mean vertical motion of the Na structure shown in Fig. 5; a 1 -h period is consistent with the $3.3 \mathrm{~km}$ wavelength shown in Fig. 3. The observed periodicity in the $\mathrm{Na}_{\mathrm{s}}$ height was consistent with a direct modulation of the neutral background by the vertical wind component of the gravity wave. The vertical motion was about $1.5 \mathrm{~km}$ and would correspond to a $14 \mathrm{~K}$ peak-peak amplitude and a $-9.3 \mathrm{~K} / \mathrm{km}$ gradient over half a vertical wavelength. This is quite close to the adiabatic limit where the potential temperature and streamlines in an altitude-time plot go vertical, thus likely explaining the observed sawtooth time dependence.

Another possibility is that the $\mathrm{Na}^{+}$reservoir was dumped with a sawtooth time dependence, and the $\mathrm{Na}_{\mathrm{S}}$ layer tracked it. This has the potential to provide a longer time interval for the ion-neutral conversion to occur and would not depend as much on the $\mathrm{Na}^{+}$chemical lifetime. However, the most likely scenario was that the ions moved downwards due to the combination of the wind-shear mechanism and the vertical electric fields to a height where the $\mathrm{Na}^{+}$ions converted rapidly to neutral sodium. Then the $\mathrm{Na}_{\mathrm{s}}$ layer was modulated in a sawtooth pattern by a gravity wave whose amplitude was sufficient to steepen its wave fronts.

We should also note that Lanchester et al. (1991) have used EISCAT incoherent scatter radar observations of Es as a tracer of gravity waves. They plotted the relative height variation of the Es layer around the average slope of the descending layer for three nights, and sawtooth waveshapes were not recognizable. However, as soon as a descending slope is reinserted, sawtooth waveshapes are apparent. Unfortunately, the resulting rising edge has a reduced slope rather than the falling edge (opposite to the MaCWAVE observation), so the steady vertical wind component must have been in the opposite direction. Obviously, more detailed model simulations are necessary to fully understand these possibilities.

Determination of the detailed physics that creates neutral metal layers has still not been fully accomplished despite many efforts (von Zahn and Hansen, 1988; Hansen and von Zahn, 1990; Kirkwood and von Zahn, 1991, 1993; Clemesha, 1995; Cox and Plane, 1998; Clemesha et al., 1999). While a number of sources that could serve as reservoirs of neutral atoms have been considered (e.g. Hansen and von Zahn, 1998), finding mechanisms that work at various latitudes and which explain observed seasonal dependencies has not been straightforward. Early observations of a strong correlation between the occurrence of sporadic $\mathrm{E}$ and sudden neutral layers (von Zahn and Kirkwood) have suggested that, at the minimum, a common "driver" is involved in both phenomena. Evidence for a more direct link was provided by Heinselman et al. (1998), who observed the formation of $\mathrm{Na}_{\mathrm{s}}$ about $30 \mathrm{~min}$ after the formation of $E_{S}$. While the $E_{S}$ time history is undersampled for the MaCWAVE data, it does not contradict a similar time delay. On the other hand, midlatitude observations of neutral metallic layers below $100 \mathrm{~km}$ have sometimes shown the development of the layer without an ion layer or even before the development of the ion layer (Friedman et al., 2000), so conversion from $\mathrm{Na}^{+}$to $\mathrm{Na}_{\mathrm{s}}$ does not seem to be the full explanation. Another difficulty is whether the $\mathrm{Na}^{+}$reservoir is large enough to supply the $\mathrm{Na}_{\mathrm{s}}$ layer, but the data of Heinselman et al. (1998) and Heinselman (2000) suggest that it was in their observations. We believe that the $\mathrm{Na}^{+}$layer was still developing at the time of the MaCWAVE rocket flight, so we cannot answer that question. The appearance of $\mathrm{Na}_{\mathrm{s}}$ at Andøya is clustered between 22:00 and 02:00 LT (Hansen and von Zahn, 1990). The dependence of the vertical ion drift on both winds and electric fields may explain this link. As discussed by Kirkwood and von Zahn (1993), a northward E field tends to suppress Es formation, while a southward field greatly speeds up its development. While the auroral electric field typically points northward in the early evening, it later changes to southward (Nygrén et al., 1984), at which time the combination of $\mathrm{E}$ field and winds provides an efficient downward movement to the lower E-region. 


\section{Summary and conclusions}

Observations of the background neutral wind in the lower E-region were made by a Na lidar during the launch of an instrumented rocket on 5 July 2003 as part of the MaCWAVE program. The observed wind had a very strong shear in the $96-98 \mathrm{~km}$ altitude region. The presence of gravity wave structure in the wind was also noted between 90 and $96 \mathrm{~km}$. Although electric fields were not measured, the effect of the winds alone were similar to the net effect produced by the sum of a wind shear and southward electric field considered in a previous measurement campaign (METAL). A mass spectrometer payload observed metallic ion layers at 95 and $96 \mathrm{~km}$ during that previous METAL flight. The Langmuir probe of this MaCWAVE instrumented rocket observed sporadic-E layers at the same altitudes.

The Na lidar data also provided a display of the vertical distribution of neutral sodium for the time interval surrounding the rocket flight. The mean downward velocity of the sporadic sodium layer was consistent with the gravity wave seen in the zonal winds. A plot of the altitude of the peaks of the $\mathrm{Na}_{\mathrm{s}}$ layer exhibits a sawtooth periodic structure that is consistent with modulation by a gravity wave whose amplitude is just below its convective limit. The data was all consistent with: the formation of an ion layer by the windshear mechanism and electric fields, movement of the layer downwards with the phase of a gravity wave, and conversion of sodium ions to neutral sodium that was then advected by the neutral vertical wind of the gravity wave. The lack of direct measurement $\mathrm{s}$ of $\mathrm{Na}^{+}$or the electric fields prevent us from making a definitive conclusion, however.

Acknowledgements. The authors gratefully acknowledge the launch support provided by personnel of the NASA Wallops Flight Facility, the Andøya Rocket Range, and the ALOMAR Observatory. The Faraday rotation experiment of M. Friedrich, Graz University of Technology, provided important absolute calibration of the electron density measurement. This research was supported by NASA grants NAG5-01075, NAS5-02036, and NAG5-5313, by the AFOSR under contract F49620-03-C-0045, and by the NSF under grants ATM-0137354 and ATM-0436703.

Topical Editor U.-P. Hoppe thanks two referees for their help in evaluating this paper.

\section{References}

Aikin, A. C., Goldberg, R. A., and Azcárraga, A.: Ion Composition during the formation of a mid-latitude Es Layer, Space Research XIV, 283-288, 1974.

Alpers, M., Blix, T., Kirkwood, S., Krankowsky, D., Lübken, F. J., Lutz, S., and von Zahn, U.: First simultaneous measurements of neutral and ionized iron densities in the upper mesosphere, J. Geophys. Res., 98, 275-283, 1993.

Axford, W. I.: The formation and vertical movement of dense ionized layers in the ionosphere due to neutral wind shears, J. Geophys. Res, 68, 769-779, 1963.
Bedey, D. F. and Watkins, B. J.: Large-scale transport of metallic ions and the occurrence of thin ion layers in the polar ionosphere, J. Geophys. Res, 102, 9675-9681, 1997.

Chimonas, G. and Axford, W. I.: Vertical movement of temperatezone sporadic E layers, J. Geophys. Res, 73, 111-117, 1968.

Clemesha, B. R.: Sporadic neutral metal layers in the mesosphere and lower thermosphere, J. Atmos. Terr. Phys., 57, 725-736, 1995.

Clemesha, B. R., Batista, P. P., and Simonich, D. M.: An evaluation of the evidence for ion recombination as a source of sporadic neutral layers in the lower thermosphere, Adv. Space Res., 24, 547-556, 1999.

Collins, S. C., Plane, J. M. C., Kelley, M. C., Wright, T. G., Soldan, P., Kane, T. J., Gerrard, A. J., Grime, B. W., Rollason, R. J., Friedman, J. S., Gonzalez, S. A., Zhou, Q. H., Sulzer, M. P., and Tepley, C. A.: A study of the role of ion-molecule chemistry in the formation of sporadic sodium layers, J. Atmos. Sol.-Terr. Phys., 64, 845-860, 2002.

Constantinides, E. and Bedinger, J. F.: Observed redistribution of E-region ionization by neutral winds, J. Atmos. Terr. Phys., 33, 461-472, 1971.

Cox, R. M. and Plane, J. M. C.: An ion-molecule mechanism for the formation of neutral sporadic Na layers, J. Geophys. Res., 103, 6349-6359, 1998.

Croskey, C. L., Mitchell, J. D., Goldberg, R. A., Blix, T. A., Rapp, M., Latteck, R., Friedrich, M., and Smiley, B.: Coordinated investigation of plasma and neutral density fluctuations and particles during the MaCWAVE/MIDAS summer 2002 program, Geophys. Res. Lett., 31, L24S08, doi:10.1029/2004GL020169, 2004.

Croskey, C. L., Mitchell, J. D., Friedrich, M., Schmidlin, F. J., and Goldberg, R. A.: In situ electron and ion measurements and observed gravity wave effects in the polar mesosphere during the MaCWAVE program, Ann. Geophys., 24, this issue, 2006.

Earle, G. D., Kane, T. J., Pfaff, R. F., and Bounds, S. R.: Ion layer separation and equilibrium zonal winds in midlatitude sporadic E, Geophys. Res. Lett., 27, 461-464, doi:10.1029/1999GL900572, 2000.

Friedman, J. S., Gonzáles, S. A., Tepley, C. A., Zhou, Q., and Sulzer, M. P.: Simultaneous atomic and ion layer enhancements observed in the mesopause over Arecibo during the Coqui II sounding rocket campaign, Geophys. Res. Lett., 27, 449-452, 2000.

Fritts, D. C., Williams, B. P., She, C. Y., Vance, J. D., Rapp, M., Lübken, F.-J., Müllemann, A., Schmidlin, F. J., and Goldberg, R. A.: Observations of extreme temperature and wind gradients near the summer mesopause during the MaCWAVE/MIDAS rocket campaign, Geophys. Res. Lett., 31, LS24S06, doi:10.1029/2003GL019389, 2004.

Fujitaka, K., Ogawa, T., and Tohmatsu, T.: A numerical computation of the ionization redistribution effect of the wind in the nighttime ionosphere, J. Atmos. Terr. Phys., 33, 687-700, 1971.

Goldberg, R. A., Fritts, D. C., Schmidlin, F. J., Williams, B. P., Croskey, C. L., Mitchell, J. D., Friedrich, M., Russell III, J. M., Blum, U., and Fricke, K. H.: The MaCWAVE program to study gravity wave influences on the polar mesosphere, Ann. Geophys., 24, this issue, 2006. 
Hansen, G. and von Zahn, U.: Sudden sodium layers in polar latitudes, J. Atmos. Terr. Phys., 52, 585-608, 1990.

Heinselman, C. J.: Auroral effects on the gas phase chemistry of meteoric sodium, J. Geophys. Res., 105, 12 181-12 192, 2000.

Jacobsen, T. A. and Friedrich, M.: Electron density measurements in the lower D-region, J. Atmos. Terr. Phys., 41, 1195-1200, 1979.

Kelley, M. C., Riggin, D., Pfaff, R. F., Swartz, W. E., Providakes, J. F., and Huang, C. -S.: Large amplitude quasi-periodic fluctuations associated with a mid-latitude sporadic E layer, J. Atmos. Terr. Phys., 57, 1165-1178, 1995.

Kirkwood, S. and Nilsson, H.: High-latitude sporadic-E and other thin layers - the role of magnetospheric electric fields, Space Science Reviews, 91, 579-613, 2000.

Kirkwood, S. and von Zahn, U.: On the role of auroral electric fields in the formation of low altitude sporadic-E and sudden sodium layers, J. Atmos. Terr. Phys, 53, 389-407, 1991.

Kirkwood, S. and von Zahn, U.: Formation mechanisms for lowaltitude Es and their relationship with neutral Fe layers: Results from the METAL campaign, J. Geophys. Res., 98, 21 549$21561,1993$.

Kwon, K. H., Senft, D. C., and Gardner, C. S.: Lidar Observations of sporadic sodium layers at Mauna Kea Observatory, Hawaii, J. Geophys. Res, 93, 14 199-14 208, 1988.

Lanchester, B. S., Nygrén, T., Huuskonen, A., Turunen, T., and Jarvis, M. J.: Sporadic E as a tracer for atmospheric waves, Planet. Space Sci., 1421-1434, 1991.

Larsen, M. F., Fukao, S., Yamamoto, M., Tsunoda, R., Igarashi, K., and Ono, T.: The SEEK chemical release experiment: Observed neutral wind profile in a region of sporadic E, Geophys. Res. Lett., 25, 1789-1792, 1998.

Mathews, J. D. and Bekeny, F. S.: Upper atmosphere tides and the vertical motion of ionospheric sporadic layers at Arecibo, J. Geophys. Res., 84, 2743-2750, 1979.

Mathews, J. D.: Sporadic E: Current views and recent progress, J. Atmos. Terr. Phys., 60, 413-435, 1998.

Mitchell, J. D., Croskey, C. L., Goldberg, R. A., and Friedrich, M.: Charged particle observations in the polar mesosphere during the MaCWAVE and DROPPS programs, ESA SP-590, 161-166, 2005.

Mori, H. and Oyama, K.-I.: Sounding rocket observation of sporadic-E electron-density irregularities, Geophys. Res. Lett., 25, 1785-1788, 1998.

Mori, H. and Oyama, K.-I.: Rocket observation of sporadic-E layers and electron density irregularities over midlatitude, Adv. Space Res. 26, 1251-1255, 2000.

Nygrén, T., Jalonen, L. Oksman, J., and Turunen, T.: The role of electric field and neutral wind direction in the formation of sporadic E-layers, J. Atmos. Terr. Phys., 46, 373-381, 1984.
Reddy, C. A., Mukunda Rao, M., and Matsushita, S.: Rocket Observations of electron densities in the night-time auroral E-Region at Fort Churchill, Canada, Planet. Space Sci., 17, 617-628, 1969.

Roddy, P. A., Earle, G. D., Swenson, C. M., Carlson, G. G., and Bullett, T. W.: Relative concentrations of molecular and metallic ions in midlatitude intermediate and sporadic-E layers, Geophys. Res. Lett., 31, doi:10.1029/2004GL020604, 2004.

She, C. Y., Williams, B. P., Hoffmann, P., Latteck, R., Baumgarten, G., Vance, J. D., Fiedler, J., Acott, P., Fritts, D. C., and Lübken, F.-J.: Simultaneous observation of sodium atoms, NLC and PMSE in the summer mesopause region above ALOMAR, Norway (69N, 12E), J. Atmos. Solar-Terr. Phys., doi:10.1016/j.jastp.2005.08.014, 2005.

Smith, L. G.: A sequence of rocket observations of night-time sporadic-E, J. Atmos. Terr. Phys, 32, 1247-1257, 1970.

Smith, L. G. and Mechtly, E. A.: Rocket observations of sporadic E layers, Radio Science, 7, 367-376, 1972.

Smith, L. G. and Miller, K. L.: Sporadic-E layers and unstable wind shears, J. Atmos. Terr. Phys., 42, 45-50, 1980.

Steinweg, A., Krankowsky, D., Lämmerzahl, P., and Anweiler, B.: Metal ion layers in the auroral lower E-region measured by mass spectrometers, J. Atmos. Terr. Phys, 54, 703-714, 1992.

Turunen, T., Nygrén, T., and Huuskonen, A.: Nocturnal highlatitude E-region in winter during extremely quiet conditions, J. Atmos. Terr. Phys., 55, 783-795, 1993.

von Zahn, U. and Hansen, T. L.: Sudden neutral sodium layers: A strong link to sporadic E layers, J. Atmos. Terr. Phys., 50, 93104, 1988.

von Zahn, U., Goldberg, R. A., Stegman, J., and Witt, G.: Doublepeaked sodium layers at high latitudes, Planet. Space Sci., 6, 657-667, 1989.

Whitehead, J. D.: The formation of sporadic-E layers in the temperate zones, J. Atmos. Terr. Phys, 20, 49-58, 1961.

Whitehead, J. D.: Difficulty associated with wind-shear theory of sporadic E, J. Geophys. Res, 76, 3127-3135, 1971.

Williams, B. P., White, M. A., Krueger, D. A., and She, C. Y.: Observation of a large amplitude wave and inversion layer leading to convective instability in the mesopause region over Fort Collins, CO (41N, 105W), Geophysical Research Letters, 29, 1850-1853, doi:10.1029/2001GL014514, 2002.

Williams, B. P., Fritts, D. C., Wang, L., She, C. Y., Vance, J. D., Schmidlin, F. J., Goldberg, R.A., Müllemann, A., Lübken, F.-J.: Gravity waves in the arctic mesosphere during the MaCWAVE/MIDAS summer rocket program, Geophys. Res. Lett., 31, L24S05, doi:10.1029/2004GL020049, 2004.

Yamamoto, M., Ono, T., Oya, H., Tsunoda, T., Larsen, M. F., Fukao, S., and Yamamoto, M.: Structures in sporadic-E observed with an impedance probe during the SEEK campaign: Comparisons with neutral-wind and radar-echo observations, Geophys. Res. Lett., 25, 1781-1784, 1998. 